\title{
Matching Network Elimination in Broadband Rectennas for High-Efficiency Wireless Power Transfer and Energy Harvesting
}

\author{
Chaoyun Song, Student Member, IEEE, Yi Huang, Senior Member, IEEE, Jiafeng Zhou, Paul \\ Carter, Sheng Yuan, Qian Xu, and Zhouxiang Fei
}

\begin{abstract}
Impedance matching networks for nonlinear devices such as amplifiers and rectifiers are normally very challenging to design, particularly for broadband and multiband devices. A novel design concept for a broadband high efficiency rectenna without using matching networks is presented in this paper for the first time. An off-center-fed dipole antenna with relatively high input impedance over a wide frequency band is proposed. The antenna impedance can be tuned to the desired value and directly provides a complex conjugate match to the impedance of a rectifier. The received RF power by the antenna can be delivered to the rectifier efficiently without using impedance matching networks, thus the proposed rectenna is of a simple structure, low cost and compact size. In addition, the rectenna can work well in different operating conditions and using different types of rectifying diodes. A rectenna has been designed and made based on this concept. The measured results show that the rectenna is of high power conversion efficiency (over $60 \%$ ) in two wide bands, which are $0.9-1.1 \mathrm{GHz}$ and $1.8-2.5 \mathrm{GHz}$ respectively, for mobile, Wi-Fi and ISM bands. Moreover, by using different diodes, the rectenna can maintain its wide bandwidth and high efficiency over a wide range of input power levels (from 0 to $23 \mathrm{dBm}$ ) and load values (from 200 to $2000 \Omega$ ). It is therefore suitable for high efficiency wireless power transfer or energy harvesting applications. The proposed rectenna is general and simple in structure without the need for a matching network hence is of great significance for many applications.
\end{abstract}

Index Terms- Broadband rectennas, impedance matching networks, off-center-fed dipole, wireless power transmission, wireless energy harvesting;

Manuscript received July 5, 2016; revised October 17, 2016 and November 14, 2016; accepted December 3, 2016. This work was supported in part by the Engineering and Physical Sciences Research Council, U.K., and in part by the Aeternum LLC.

C. Song, Y. Huang, J. Zhou, S. Yuan and Z. Fei are with the Department of Electrical Engineering and Electronics, University of Liverpool, Liverpool L69 3GJ, U.K. (email: sgcsong2@liv.ac.uk; Corresponding author: $Y i$ Huang; phone: +44-151-794-4521; fax: +44-151-794-4540; e-mail: Yi. Huang @ liv.ac.uk).

Q. Xu is with College of Electronic and Information Engineering, Nanjing University of Aeronautics and Astronautics, Nanjing 211106, China. (email: emxu@foxmail.com).

P. Carter is with Global Wireless Solutions, Inc., Dulles, VA 20166 USA. (email: pcarter@gwsolutions.com).

\section{INTRODUCTION}

MPEDANCE matching is a basic but crucial concept in electronics and electrical engineering, since it can maximize the power transfer from a source to a load or minimize the signal reflection from a load. In the wireless industry today, there have been many devices (such as oscillators, inverters, amplifiers, rectifiers, power dividers, boost converters) and systems that have a high demand for impedance matching networks. A number of techniques for the network design have been reported [1]-[6]. Among them, rectifiers and power amplifiers normally utilize nonlinear elements such as diodes and transistors in the circuits. Hence their input impedance varies with the frequency, input power and load impedance. The impedance matching networks for such nonlinear circuits become very challenging to design.

Wireless power transfer (WPT) and wireless energy harvesting (WEH) have attracted significant attention in the past few years [7]-[10]. In both radiative and inductive wireless power transmissions, the rectifiers are a vital device for converting $\mathrm{AC}$ or RF power to $\mathrm{DC}$ power, while impedance matching networks are required to achieve high conversion efficiency [9].

A rectifying antenna (rectenna) is one of the most popular devices for WPT and WEH applications, and much progress has been made [11]-[19]. Multiband and broadband rectennas [15]-[19] can receive or harvest RF power from different sources and from different channels simultaneously, thus they outperform the conventional single band rectennas [11]-[14] in terms of overall conversion efficiency as well as total output power. However, the design of the impedance matching network for broadband or multiband rectennas is very challenging, and the structure of the matching network is relatively complex which may increase the cost and loss, and also introduce errors in manufacture.

Some techniques such as resistance compression networks and frequency selective networks, have been developed to reduce the non-linear effects of the rectenna [20]-[24] so that the performance can be maintained in different operating conditions. But, they all require introduction of further circuit components in the matching network which increases the 
complexity of the overall design. Using more components could increase the loss and decrease the overall efficiency. A need exists therefore for rectennas comprising simple structures with competitive performance. It is desirable that the impedance matching network is eliminated or simplified, but the received RF power at different frequency bands can still be delivered to the rectifier with high RF-DC conversion efficiency.

Some designs use a standard antenna with $50 \Omega$ impedance to match with a rectifier. Thus either the operating bandwidth is narrow [25], or the conversion efficiency over the broadband is low, typically $<20 \%$ [26]. So far there are no available designs without matching networks, that can produce high conversion efficiency over a wide frequency band, and there are no available approaches that can tune the antenna impedance to the desired value to match with the impedance of the rectifier.

In this paper, we propose a novel methodology for a high efficiency broadband rectenna without the use of a matching network. The concept and operating mechanism are introduced in Section II. The approaches for designing a broadband high impedance antenna are discussed in Section III. The rectenna integration that can eliminate the use of matching networks is shown in Section IV. The experimental validations and measurements of a fabricated rectenna example are shown in Section V. To the best of our knowledge, the proposed design is the first broadband rectenna without using matching networks and achieves good performance; that is, high RF-DC conversion efficiency and improved linearity over a wide frequency band, a range of input power levels and load impedance.

\section{NOVELTY OF THIS WORK}

A conventional rectifying antenna system, as shown in Fig. 1, normally consists of five different parts:

1) A receiving antenna which is configured to receive RF signals from a predetermined source (WPT) or to receive random signals in the ambient environment (WEH). The input impedance of the antenna is usually matched to standard $50 \Omega$; 2) A band pass filter to reject the higher order harmonic signals generated by the rectifier, since the signals could be radiated by the antenna which might reduce the overall conversion efficiency and cause interference. The filter can either be embedded with the antenna to produce a filtering-antenna structure [27] or be integrated with the impedance matching network [18] to make the complete design simple and compact; 3) An impedance matching network which is configured to match the complex impedance of the rectifier to a resistive port (e.g. $50 \Omega$ ). Thus the power of the received signals could be fully delivered to the rectifier;

4) A rectifier which is configured to convert RF power to DC power. The input impedance of the rectifier varies in a wide range of values and the impedance is very sensitive to the variation of frequency, input power and load impedance;

5) A load which could typically be a resistor, a DC-to-DC boost converter for realizing a higher output voltage, or a super capacitor to store energy.

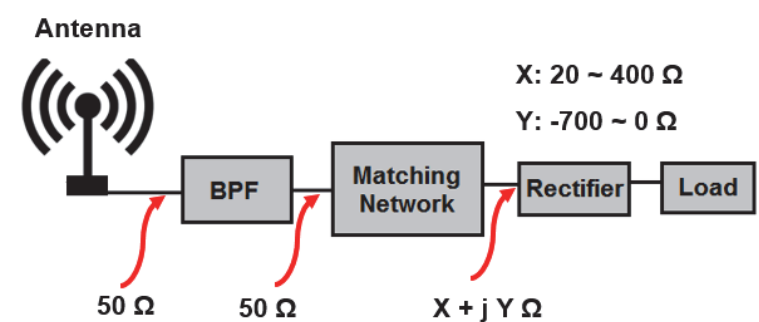

Fig. 1. Configuration of a conventional rectifying antenna system with impedance matching networks.

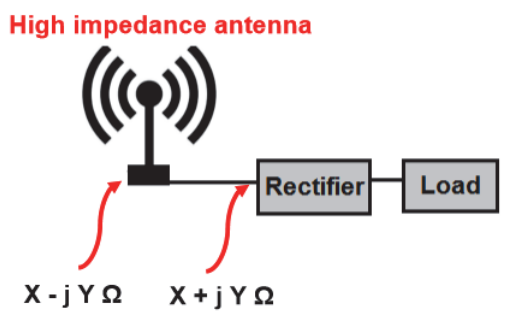

Fig. 2. Configuration of the proposed rectifying antenna without using impedance matching networks.

In previous studies [18], [24], the impedance of the rectifier was analysed under different operating conditions such as a wide frequency range (e.g., $0.5-3 \mathrm{GHz}$ ), a range of input powers (e.g., -40 to $0 \mathrm{dBm}$ ) and a wide load impedance range (e.g., 1 to $100 \mathrm{k} \Omega$ ). It is concluded that the input impedance of the rectifier varies significantly (20 to $400 \Omega$ for the real part, 0 to $-700 \Omega$ for the imaginary part) over these operating conditions. Furthermore, due to nonlinearity, the impedance of the rectifier would also vary with different types of rectifying diodes and different circuit topologies. However, as shown in Fig. 1, most parts are connected by using a $50 \Omega$ port in the conventional rectenna configuration. Therefore, the design of the impedance matching network is usually the most challenging part, particularly in multiband or broadband rectennas. Thus in previous work [19] [24], the structures of the impedance matching networks were complex for broadband and multiband rectennas, while the number of circuit components used in the matching network were very large (i.e., over 25 elements) to reduce the non-linear effects and produce a consistent performance. Consequently, the complex matching networks may introduce errors from manufacture, increase the cost and loss, and create additional problems.

In this work, we propose a novel method for broadband or multiband rectenna designs. The aim is to eliminate the need for impedance matching networks and to improve the overall performance of the rectenna. As shown in Fig. 2, the proposed new configuration only consists of three parts, wherein the antenna is changed to a special high impedance antenna which is very different from conventional ones. The impedance of the antenna is around 200 to $300 \Omega$ for the real part and 0 to $300 \Omega$ for the imaginary part in desired frequency band. The value of the antenna impedance $(\mathrm{X}-\mathrm{jY})$ may directly conjugate match with the input impedance of a specific rectifier $(X+j Y)$ within the desired frequency range but mismatch at other frequencies (to produce a filtering response), as depicted in Fig. 2. Thus a matching network can be eliminated and the proposed rectenna 
can offer high conversion efficiency over a broad bandwidth. Moreover, since both the rectifier and the antenna are of relatively high input impedance, the effects on the reflection coefficient $\left(S_{11}\right)$ of the rectenna caused by the impedance variation of the nonlinear elements (rectifying diodes) may not be very significant. Therefore, compared with the conventional $50 \Omega$ (low impedance) matching system, the non-linear effects of the rectenna can be significantly reduced by using this new configuration. The rectenna may have a good performance in a range of operating conditions such as different input power levels, different load values, or even different types of rectifying diodes. In addition, the proposed rectenna configuration can reduce the total cost and avoid fabrication errors due to its very simple structure.

\section{HIGH IMPEDANCE ANTENNA DESIGN}

\section{A. Off-Center-Fed Dipole Theory}

There have been various types of high impedance antenna reported in literature [28] [29], but none of them can provide a constantly high impedance over a wide frequency range which is very important for realizing the proposed broadband high efficiency rectenna. There are no available approaches that can tune the antenna impedance over a wide frequency band to the desired values. Consequently, if these high impedance antennas were used without matching networks, the bandwidth of the rectenna could become very narrow.

Here, we propose a broadband high impedance antenna, the off-center-fed dipole (OCFD) antenna.

As depicted in Fig. 3, the OCFD antenna is different from a conventional center-fed symmetrical dipole antenna, where the two dipole arms are asymmetrical and have unequal lengths. The typical application of the OCFD is to realize a multiband antenna, since the resonant center-fed dipole has its fundamental frequency at $f_{0}$ and harmonics at $3 f_{0}, 5 f_{0}, 7 f_{0}$, and so on. While the OCFD can resonate at $f_{0}, 2 f_{0}, 4 f_{0}$, and $8 f_{0}$ by offsetting the feed by $\lambda / 4$ from the center [30]. Such OCFDs are very popular in the amateur radio community. Recently, some researchers use the OCFD to create a 90-degree phase delay and generate circular polarization radiation field for the antenna [31]. But, one of the major problems of the OCFD is that the radiation resistance of the antenna could be very high, thus it is required to use a $4: 1$ or $6: 1$ balun transformer to convert the impedance to the feeding port $50 \mathrm{ohms}$ resistance [32]. This is a disadvantage for most of those applications using OCFDs (in a conventional $50 \Omega$ feed system), but we may take advantage of this feature in the proposed rectenna design. The OCFD antenna may be well matched to a rectifier without using matching networks since the rectifiers are normally of high input impedance as well. If we assume a half wavelength center-fed dipole and an OCFD having the same total length and radiating the same power, as shown in Fig. 3. The currents at the feed points for the symmetrical and asymmetrical dipoles are $I_{S}$ and $I_{A S}$ respectively. From [38], the relationship between the currents can be expressed as

$$
I_{A S}=I_{S} \sin \alpha
$$

where $\alpha$ is the measured angle from one end in electrical
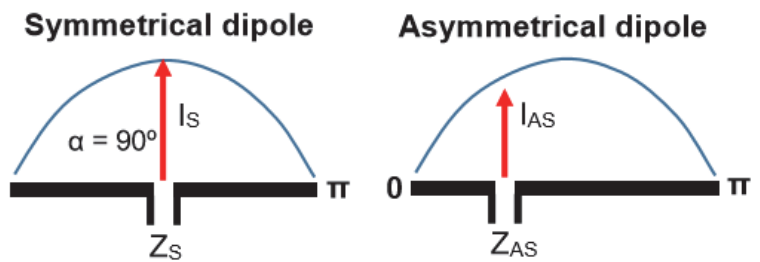

Fig. 3. The half wavelength center-fed symmetrical dipole and the off-center-fed asymmetrical dipole.

TABLE I

SIMULATED INPUT IMPEDANCE OF THE OFF-CENTER-FED DIPOLE

\begin{tabular}{cccc}
\hline \hline $\begin{array}{c}\text { Long arm } \\
(\mathrm{mm})\end{array}$ & $\begin{array}{c}\text { Short arm } \\
(\mathrm{mm})\end{array}$ & $\begin{array}{c}\text { Real part } \\
\text { at } f_{0}(\Omega)\end{array}$ & $\begin{array}{c}\text { Imaginary part } \\
\text { at } f_{0}(\Omega)\end{array}$ \\
\hline 90 & 10 & 320 & -213 \\
80 & 20 & 165 & -30 \\
70 & 30 & 102 & -0.8 \\
60 & 40 & 79 & 5.6 \\
50 & 50 & 73 & 6.4 \\
\hline \hline
\end{tabular}

degrees (between 0 and $\pi$ as shown in Fig. 3). Thus, the power radiated by both antennas can be calculated as

$$
\begin{gathered}
P_{S}=I_{S}^{2} R_{S} \\
P_{A S}=I_{A S}^{2} R_{A S}
\end{gathered}
$$

where $R_{S}$ and $R_{A S}$ are the radiation resistances of the center-fed dipole and the OCFD respectively. Since we have assumed $P_{S}=$ $P_{A S}$, thus we can obtain

$$
\frac{R_{S}}{R_{A S}}=\frac{I_{A S}^{2}}{I_{S}^{2}}
$$

Using (1), the relationship between the radiation resistances $R_{S}$ and $R_{A S}$ can be written as

$$
R_{S}=\frac{R_{A S}}{(\sin \alpha)^{2}}
$$

Thus, when $\alpha=90^{\circ}$ or $(\pi / 2)$, the dipole is center-fed since $\sin \alpha$ $=1$ and $R_{S}=R_{A S}$. It is demonstrated that the value of $R_{A S}$ is always larger than the value of $R_{S}$ if the dipole is off-center-fed. In addition, we could tune the radiation resistance of the OCFD to a desired value by changing the value of $\sin \alpha$ (position of the feed point).

In order to gain a better understanding, we study a simple OCFD antenna in free space with the aid of the CST software. Assume that the arms of the dipole are made by perfect electric conductor (PEC) wires with a diameter of $1 \mathrm{~mm}$. The total length of the OCFD is $100 \mathrm{~mm}$ while the feeding port separation is $1 \mathrm{~mm}$. If the antenna is considered as a typical half wavelength dipole, then the fundamental frequency should be about $1.5 \mathrm{GHz}$. The computed real part and imaginary part of the input impedance of the OCFD at $1.5 \mathrm{GHz}$ are given in Table I for different feed locations. As can be seen from the table, the radiation resistance of the dipole is $73 \Omega$ when the two arms have the same length. By changing the feed position, the radiation resistance can be increased where the value is about $320 \Omega$ for the long arm being $90 \mathrm{~mm}$ and the short arm being 10 $\mathrm{mm}$. Compared with the impedance of a symmetrical dipole (73 $\Omega$ ), the OCFD has increased the impedance value up to 4.4 times. The imaginary part of the input impedance is around $0 \sim$ $6 \Omega$ and the ratio of the long arm over the short arm is less than 
$7 / 3$. Therefore, if the symmetrical dipole is of a broad bandwidth, the OCFD may produce constantly high impedance over the bandwidth of interest.

\section{B. Broadband OCFD Antenna Design}

A broadband center-fed symmetrical dipole is proposed as the starting point to design a broadband OCFD antenna. As shown in Fig. 4(a), the arms of the dipole are shaped as radial (bowtie) stubs to broaden the frequency bandwidth. The bowtie dipole antenna is a planar version of a biconical antenna. From [36], the characteristic impedance $\left(Z_{k}\right)$ of an infinite biconical antenna is given by

$$
Z_{k}=120 \text { In } \cot (\theta / 4)
$$

where $\theta$ is the cone angle. Then the input impedance $\left(Z_{i}\right)$ of the biconical antenna with a finite length can be written as

$$
Z_{i}=Z_{k} \frac{Z_{k}+j Z_{m} \tan \beta l}{Z_{m}+j Z_{K} \tan \beta l}
$$

where $\beta=2 \pi / \lambda$ ( $\lambda$ is the wavelength), $l=$ cone length, and $Z_{m}=$ $R_{m}+j X_{m}$. While the values of $R_{m}$ and $X_{m}$ are given by Schellkunoff [37] for a thin biconical antenna $\left(\theta<5^{\circ}\right)$. As indicated in [36], the VSWR of the biconical antenna can be less than 2 over a 2:1 bandwidth. Meanwhile, the input impedance of the bowtie dipole is similar to that of the biconical antenna, where the value of the impedance is a function of frequency, length of the $\operatorname{arm}(R)$ and cone angle $(\theta)$.

$$
\text { TABLE II }
$$

SIMULATED FREQUENCY BANDWIDTH OF THE BOWTIE DIPOLE

\begin{tabular}{cccc}
\hline \hline & $\mathrm{R}=40 \mathrm{~mm}$ & $\mathrm{R}=50 \mathrm{~mm}$ & $\mathrm{R}=60 \mathrm{~mm}$ \\
\hline$\theta=10^{\circ}$ & $1.93-2.14 \mathrm{GHz}$ & $1.83-1.93 \mathrm{GHz}$ & $1.58-1.97 \mathrm{GHz}$ \\
$\theta=30^{\circ}$ & $1.93-2.28 \mathrm{GHz}$ & $1.75-2.17 \mathrm{GHz}$ & $1.58-1.98 \mathrm{GHz}$ \\
$\theta=50^{\circ}$ & $1.91-2.25 \mathrm{GHz}$ & $1.73-2.19 \mathrm{GHz}$ & $1.55-2 \mathrm{GHz}$ \\
$\theta=70^{\circ}$ & $1.91-2.28 \mathrm{GHz}$ & $1.73-2.21 \mathrm{GHz}$ & $1.55-2.03 \mathrm{GHz}$
\end{tabular}

The aforementioned theories could be utilized to predict the initial performance (such as the frequency bandwidth) of this broadband antenna with a given dimension. But the actual performance might be varied in the simulation and measurement due to the practical configuration of the antenna (e.g., effects of PCB and feed). Therefore, in order to maintain the antenna performance, the major design parameters of the antenna should be further tuned using the software. As a design guide, the parametric effects (values of the $R$ and $\theta$ ) on the frequency bandwidth of the bowtie dipole (as shown in Fig. 4(a)) are studied. If the antenna is printed on a Rogers RT6002 board with a relative permittivity of 2.94 and a thickness of 1.52 $\mathrm{mm}$. and it is fed by a pair of coplanar striplines (CPS) where the length $(L)$ of each strip is $32 \mathrm{~mm}$ and the width $(W)$ is 1.5 $\mathrm{mm}$. The gap between the CPS is $1 \mathrm{~mm}$. The antenna is modelled using the CST software. The simulated frequency bandwidth (for VSWR $<2$ with $50 \Omega$ port) of the bowtie dipole is shown in Table II for different cone angles and lengths of the arm.

From the results in Table II, it can be seen that the bowtie symmetrical dipole is indeed of a broad bandwidth. Moreover,

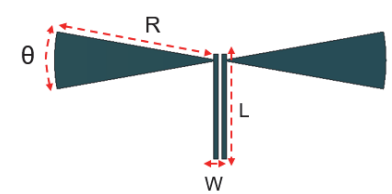

(a)

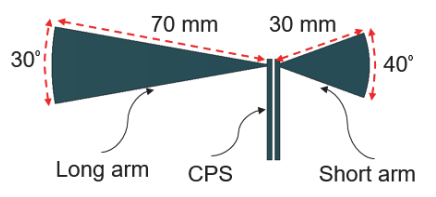

(b)
Fig. 4. (a) The broadband center-fed symmetrical dipole antenna. (b) The broadband off-center-fed dipole antenna.

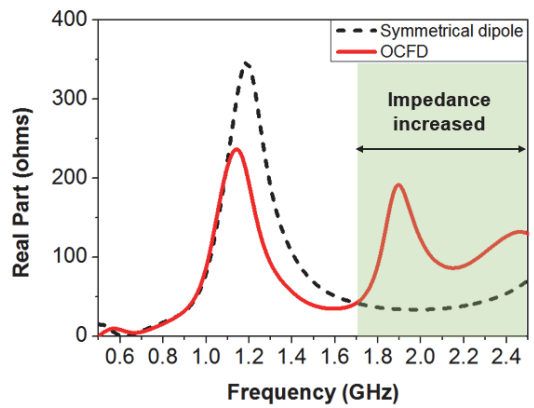

Fig. 5. The simulated real part of the impedance of the symmetrical dipole and the OCFD.

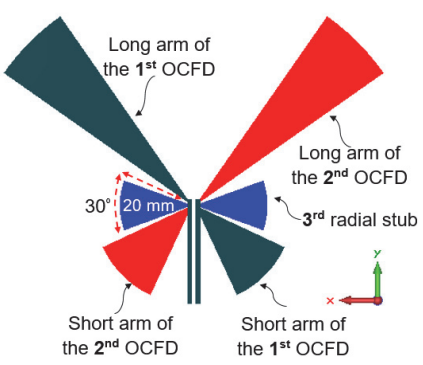

(a)

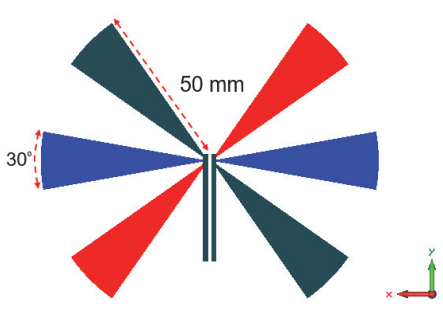

(b)
Fig. 6. (a) The proposed crossed off-center-fed dipole antenna. (b) The reference antenna with symmetrical arms for performance comparison.

the antenna could have a larger frequency bandwidth for larger cone angles, and have a lower resonant frequency band for larger dimensions (length of the arm). In this work, we select $R$ $=50 \mathrm{~mm}$, and $\theta=30^{\circ}$ as an example, since the frequency band (from 1.75 to $2.17 \mathrm{GHz}$ ) has covered some popular mobile frequency bands such as the GSM1800 and UMTS2100. Hence, the arms of the symmetrical bowtie dipole have a radius of 50 $\mathrm{mm}$ and an angle of $30^{\circ}$ for the radial stub structure. The maximum total length of the complete dipole antenna is about $100 \mathrm{~mm}$.

To design the OCFD, the length of the longer arm is increased to $70 \mathrm{~mm}$ while the length of the shorter arm is therefore reduced to $30 \mathrm{~mm}$. In addition, in order to enhance asymmetry between the arms, the circumference angle of the shorter arm is increased to $40^{\circ}$. The total length of the dipole is still of around $100 \mathrm{~mm}$, as shown in Fig. 4(b). But the ratio of the long arm and the short arm has been changed from $5 / 5$ to $7 / 3$. In this scenario, the real part of the impedance over the frequency band may be increased while the imaginary part could be maintained over the resonant frequency band (as discussed in Table I). Fig. 5 shows the simulated real part of the input impedance of the symmetrical dipole and the OCFD. It can be seen that the impedance of the symmetrical dipole is around $50 \Omega$ for frequencies between 1.75 and $2.4 \mathrm{GHz}$ (around the $2^{\text {nd }}$ and $3^{\text {rd }}$ resonant frequency bands), which verifies the 


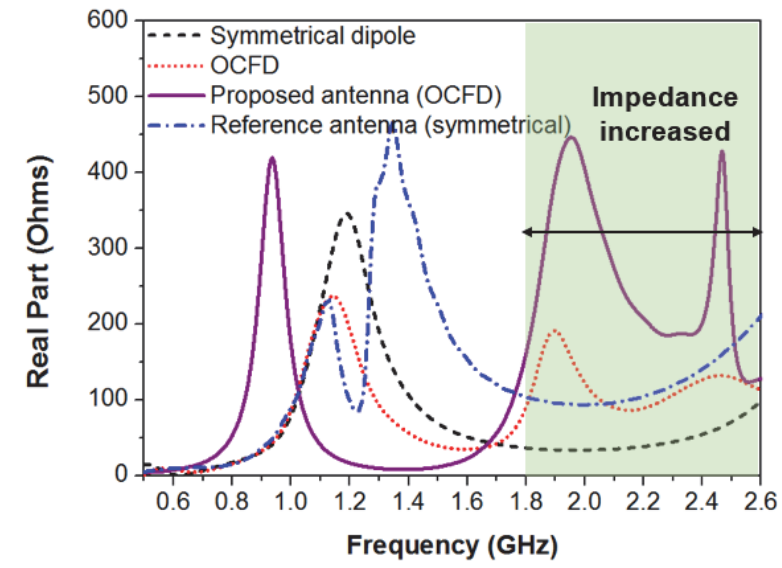

(a)

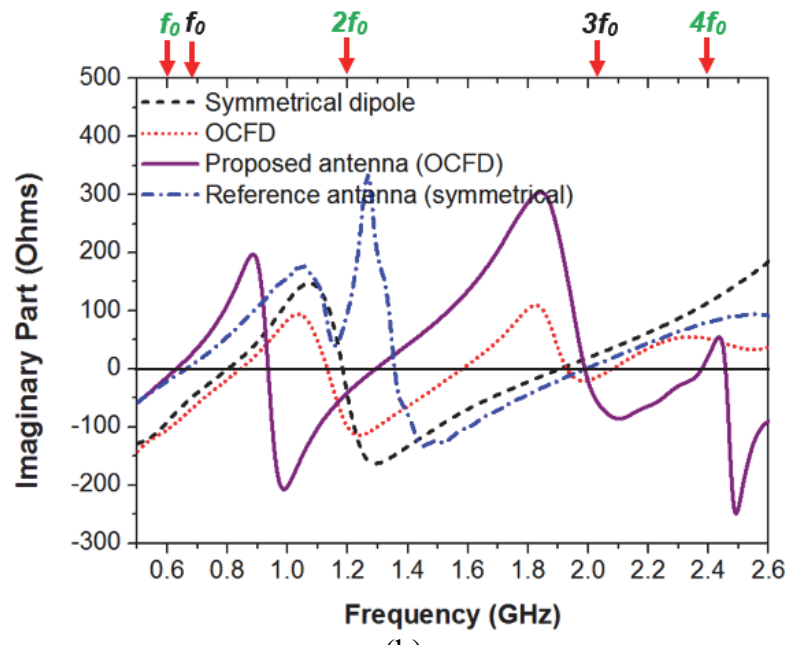

(b)

Fig. 7. The simulated input impedance of four different antennas; (a) Real part. (b) Imaginary part.

broadband performance of the antenna as depicted in Table II. However, the impedance of the OCFD is from 100 to $200 \Omega$ over the frequency band between 1.8 and $2.5 \mathrm{GHz}$, which is much higher than that of the symmetrical dipole. It is shown that, by modifying a broadband symmetrical bowtie dipole to an OCFD, the antenna impedance is significantly increased over the desired resonant frequency range. In addition, the impedance for both antennas at the frequencies from 1.1 to 1.2 $\mathrm{GHz}$ is also very high (i.e. over $200 \Omega$ ), this is due to the anti-resonance of the dipole antenna [31].

The next step is to modify the proposed OCFD to a crossed OCFD by introducing another OCFD. As shown in Fig. 6 (a), the second OCFD (red) having the same dimensions as the first one, but they are orthogonal to each other. The purpose is to achieve dual polarization receiving capability and generate a vertically symmetrical radiation pattern for the antenna. Finally, another pair of radial stubs (blue) is inserted between the two OCFDs to further manipulate the impedance. The final antenna layout is show in Fig. 6(a) which looks symmetrical from left to right as a whole. For comparison, a reference antenna consisting of three dipoles with symmetrical arms is studied. As shown in Fig. 6(b), the arms of the reference
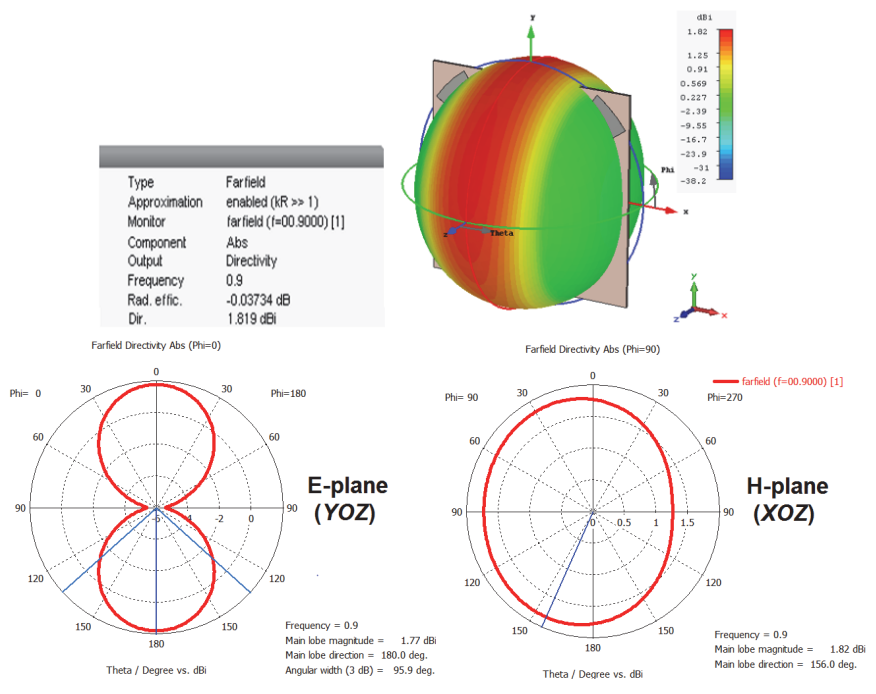

(a)

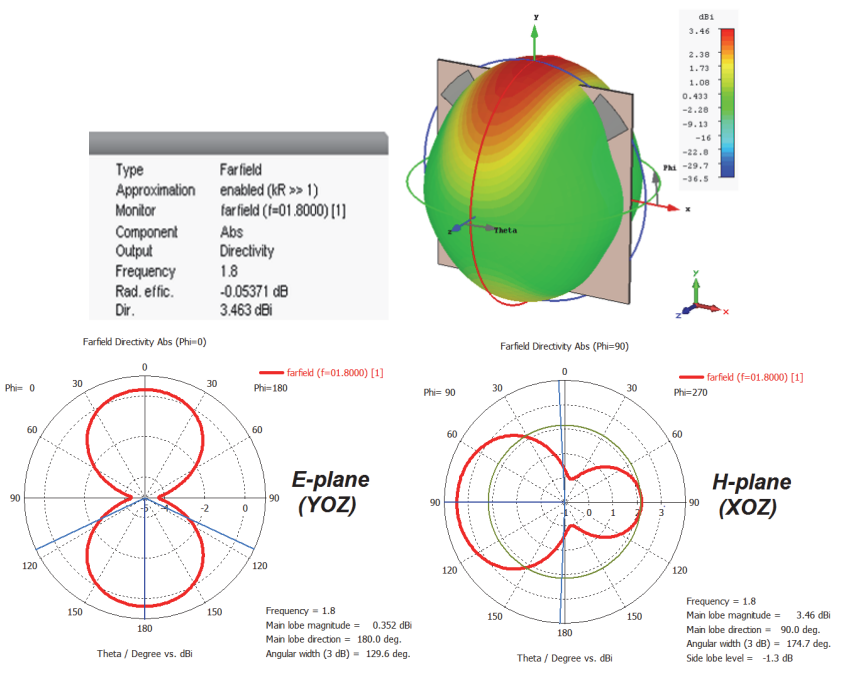

(b)
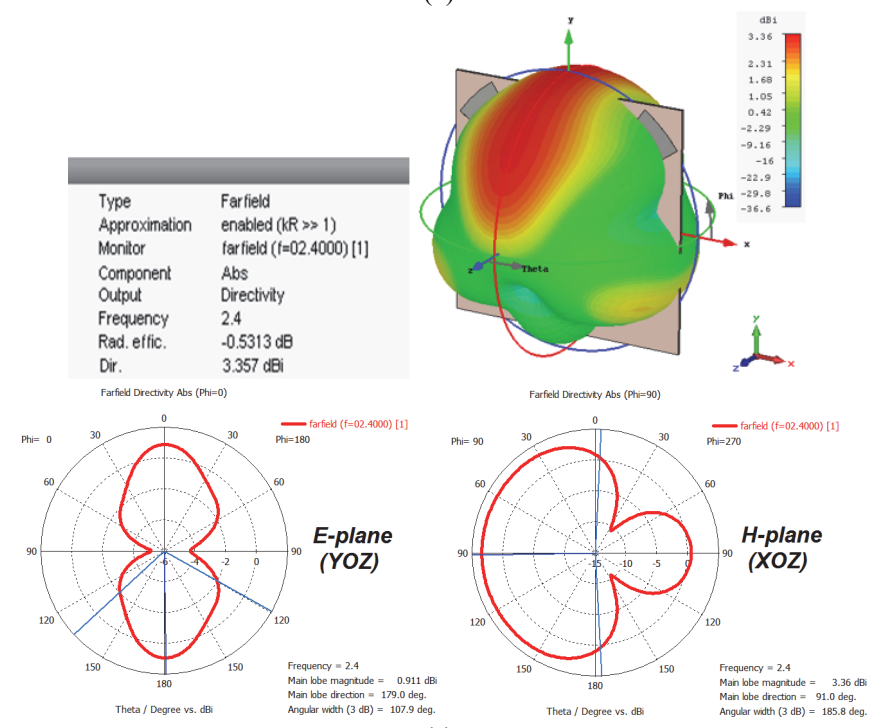

(c)

Fig. 8. The simulated 3D patterns with directivities and 2D patterns over E-plane and H-plane of the proposed antenna at (a) $0.9 \mathrm{GHz}$, (b) $1.8 \mathrm{GHz}$, and (c) $2.4 \mathrm{GHz}$ 


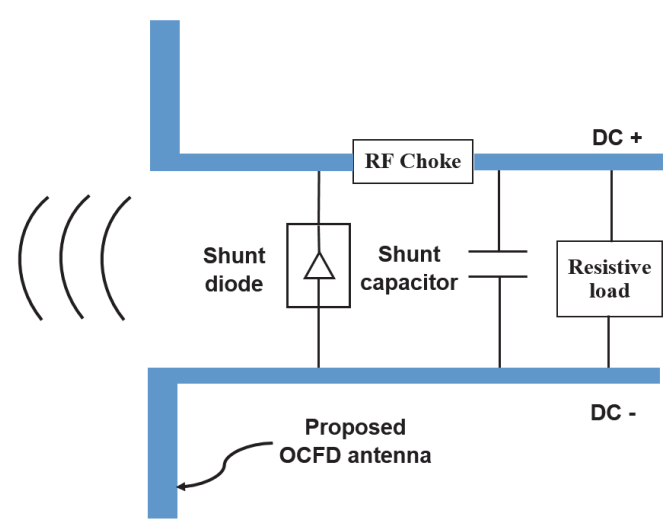

Fig. 9. Configuration of a single shunt diode (Class F) rectifier with a dipole antenna.

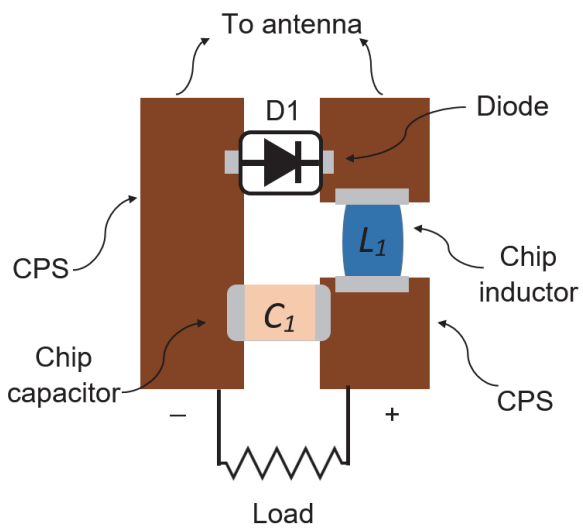

Fig. 10. Configuration of the proposed rectifier on coplanar striplines (CPS).

TABLE III

CIRCUIT COMPONENTS USED IN THE DESIGN

\begin{tabular}{ccc}
\hline \hline $\begin{array}{c}\text { Component } \\
\text { name }\end{array}$ & Nominal Value & Part number and supplier \\
\hline D1 & Schottky diode & SMS7630-079LF, Skyworks \\
L1 & $47 \mathrm{nH}$ chip inductor & $\begin{array}{c}\text { 0603HP47N, Coilcraft } \\
\text { 100 nF }\end{array}$ \\
C1 & $\begin{array}{c}\text { GRM188R71H104JA93D, } \\
\text { chip capacitor }\end{array}$ \\
\hline \hline
\end{tabular}

antenna have a radius of $50 \mathrm{~mm}$ and a circumference angle of $30^{\circ}$ for the radial stub. Thus the reference antenna and the proposed antenna have the same electrical length $(100 \mathrm{~mm})$. The simulated real part and imaginary part of the input impedance of four different antennas (single symmetrical dipole, single OCFD, proposed OCFD, and reference antenna) are shown in Figs. 7(a) and (b). It can be seen that the real part of the input impedance of the proposed broadband OCFD antenna is above $180 \Omega$ (up to $450 \Omega$ ) for the frequency band between $1.8 \mathrm{GHz}$ and $2.5 \mathrm{GHz}$, which is much higher than that of the reference antenna (around $100 \Omega$ ). In addition, the proposed antenna has shifted the high-impedance (about 400 $\Omega$ ) frequency from around $1.4 \mathrm{GHz}$ to around $0.9 \mathrm{GHz}$. This is likely due to the coupling effects among the three dipoles. The imaginary part of the reference antenna is around $0 \Omega$ at frequencies around $0.7 \mathrm{GHz}$ and $2.1 \mathrm{GHz}$, which are $f_{0}$ and $3 f_{0}$ respectively. While the imaginary part of the proposed OCFD is around $0 \Omega$ at resonant frequencies $0.6 \mathrm{GHz}, 1.2 \mathrm{GHz}$ and 2.4 $\mathrm{GHz}$, which are $f_{0}, 2 f_{0}$, and $4 f_{0}$ respectively. These results have demonstrated that the simulated results agree with the OCFD theory as discussed in Section III-A. Furthermore, the imaginary part of the impedance of the antenna over the resonant frequency band from 1.4 to $2 \mathrm{GHz}$ turns from negative values (for the reference antenna) to positive values (for the proposed antenna). As shown in Fig. 7(b), the value of the imaginary part of the proposed antenna impedance varies between 0 and $300 \Omega$ over the desired frequency band. This feature could help the proposed antenna to produce a better conjugate matching with the rectifier, since the imaginary part of the impedance of the rectifier normally varies between -700 and $0 \Omega$ as we discussed earlier. The simulated $3 \mathrm{D}$ radiation patterns of the proposed antenna at the frequencies of interest are depicted in Fig. 8. The 2D polar plots of antenna patterns in E-plane and H-plane are shown as well. Here we have only showed the directivity (maximum gain) of the antenna (without taking the mismatch loss into account). From Fig. 8, it can be seen that the antenna has symmetrical patterns about YOZ plane with a maximum directivity of $1.8 \mathrm{dBi}$ at $0.9 \mathrm{GHz}, 3.5$ $\mathrm{dBi}$ at $1.8 \mathrm{GHz}$ and $3.3 \mathrm{dBi}$ at $2.4 \mathrm{GHz}$. The antenna is more directive towards the long arm direction at $1.8 \mathrm{GHz}$ and 2.4 $\mathrm{GHz}$ with the half-power beam-widths (HPBW) of around $174^{\circ}$ and $185^{\circ}$ respectively. The HPBW is about $96^{\circ}$ at $0.9 \mathrm{GHz}$.

Therefore, the proposed broadband OCFD antenna has obtained high impedance over a wide frequency range. The proposed design is just an example to illustrate the proposed new method. The details of the dipole could be modified according to the frequency of interest.

\section{RECTENNA INTEGRATION}

\section{A. Rectifier Configuration}

The proposed high impedance OCFD antenna may directly conjugate match with the input impedance of a rectifier over a wide frequency band. The rectifier should only consist of few circuit components for rectification, DC storage and output. A single shunt diode rectifier is selected due to its very simple structure and high conversion efficiency [33]. The configuration of the single shunt diode rectifier with a dipole antenna is depicted in Fig. 9. The shunt diode is used as the rectifying element and the diodes for high frequency (e.g., $\mathrm{f}>1$ $\mathrm{GHz}$ ) applications are normally Schottky diodes such as SMS7630 (from Skyworks) and HSMS2860 (from Avago). A shunt capacitor after the diode is used to store DC power and smooth the DC output waveforms. In addition, a series connected RF choke is placed between the diode and capacitor to block AC components generated from the diode. In this design, a typical inductor of $47 \mathrm{nH}$ is selected as the RF choke. To have a better configuration on the PCB, the proposed antenna and rectifier are both fed by CPS (or twin-wire conducting strips). The topology of the rectifier configured with the conducting strips extended from the OCFD antenna is shown in Fig. 10. The values and part numbers of the circuit components are given in Table III. 


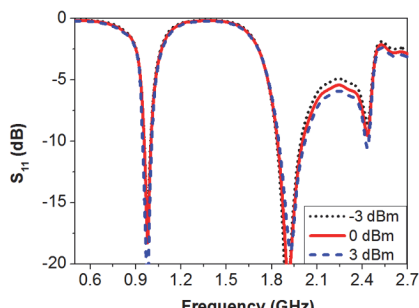

(a)

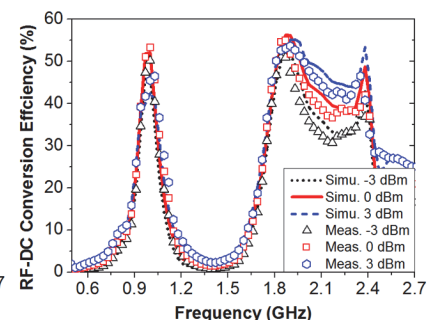

(b)
Fig. 11. (a) The simulated $\mathrm{S}_{11}$ and (b) the simulated and measured RF-DC conversion efficiency of the rectenna at three different input power levels. The load resistance is $400 \Omega$.

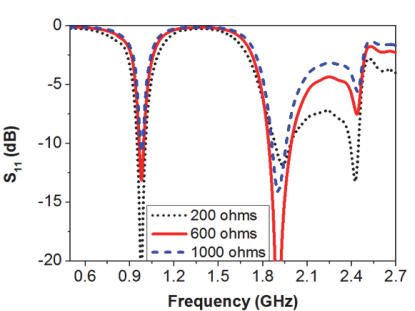

(a)

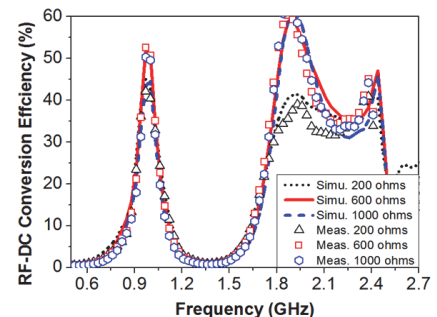

(b)
Fig. 12. (a) The simulated $\mathrm{S}_{11}$ and (b) the simulated and measured RF-DC conversion efficiency of the rectenna at three different load values. The input power level is $0 \mathrm{dBm}$.

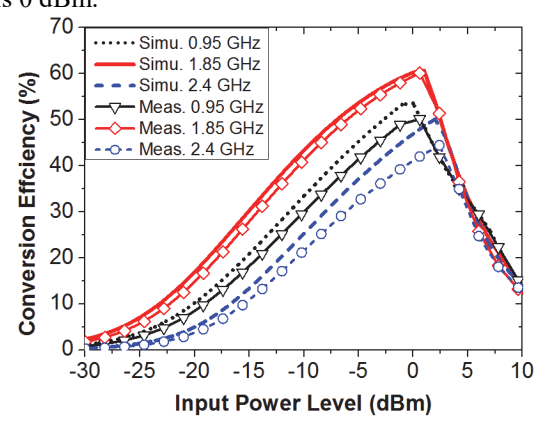

Fig. 13. The simulated and measured conversion efficiency of the rectenna versus input power level at three frequencies. The load resistance is $600 \Omega$.

The rectifier is built and simulated by using the ADS software. To improve the accuracy of results, the diode is modelled by using a non-linear SPICE model with parasitic elements provided by the suppliers (such as Skyworks). The chip inductor and capacitor are modelled by using the real product models, including the S-parameter files, provided by Murata and Coilcraft. Since the proposed design can eliminate the matching network between the antenna and the rectifier, thus the rectifying circuit is indeed simplified. The frequency domain power source port is used in the simulation, and the port impedance is defined as the impedance of the proposed OCFD antenna by using the touchstone S1P files exported from the CST, similarly to the results shown in Figs. 7(a) and (b).

\section{B. Rectenna Performance}

After the complete rectenna has been designed, its performance is evaluated by using the Harmonic Balance (HB) simulation and the Large Signal S-Parameter (LSSP) simulation using the ADS. The performances of the proposed rectenna in terms of the reflection coefficient $\left(\mathrm{S}_{11}\right)$ and RF-DC conversion efficiency are shown in Figs. 11 to 13. The RF-DC conversion efficiency is obtained by

$$
\eta_{R F-D C}=\frac{P_{D C}}{P_{\text {in }}}
$$

where $P_{D C}$ is the output DC power and Pin is the input RF power to the antenna. The $\mathrm{S}_{11}$ (simulated) and conversion efficiency (simulated and measured) of the rectenna at different input power levels are shown in Figs. 11(a) and (b) as a function of frequency. A typical load resistor of $400 \Omega$ is selected. From Fig. 11, it can be seen that the rectenna covers the desired broad frequency band from 1.8 to $2.5 \mathrm{GHz}$ and an additional frequency band around $1 \mathrm{GHz}$. The $\mathrm{S}_{11}$ of the rectenna is lower than $-10 \mathrm{~dB}$ between 1.8 and $2 \mathrm{GHz}$ and around $1 \mathrm{GHz}$. The conversion efficiency is higher than $40 \%$ (up to $55 \%$ ) over the entire frequency band of interest for the input power level of $0 \mathrm{dBm}(1 \mathrm{~mW})$. In addition, when the input power is doubled $(3 \mathrm{dBm})$ or halved $(-3 \mathrm{dBm})$, the reflection coefficients are always smaller than $-6 \mathrm{~dB}$ from 1.8 to $2.5 \mathrm{GHz}$, while the efficiency over the band of interest is still high (e.g., greater than $35 \%$ ).

Figs. 12 (a) and (b) depict the $\mathrm{S}_{11}$ (simulated) and conversion efficiency (simulated and measured) of the rectenna for different load values. It can be seen that the efficiency is higher than $30 \%$ (up to $60 \%$ ) for the load values from 200 to $1000 \Omega$ and for the frequencies between 1.8 and 2.5 and the around $1 \mathrm{GHz}$. It is demonstrated that the nonlinear effects linked to the input power and load are reduced in the proposed broadband rectenna, which verifies our predictions in Section II. The simulated and measured conversion efficiency of the rectenna versus input power level is shown in Fig. 13 at three frequencies. It can be seen that the rectenna has the highest efficiency at the input power of around $0 \mathrm{dBm}$. This is because the selected diode (SMS7630) has reached its reverse breakdown voltage. Since this diode has a very low forward bias voltage $(150 \mathrm{mV})$ and a low breakdown voltage (2 V) [34], it is normally applied in low input power (e.g., from -30 to 0 $\mathrm{dBm}$ ) applications. For high input power applications (e.g., > $10 \mathrm{dBm}$ ) and higher conversion efficiency (e.g., up to $80 \%$ ), other diodes with a higher breakdown voltage could be selected.

\section{RECTENNA MEASUREMENTS AND VALIDATIONS}

The fabricated prototype rectenna is shown in Fig. 14 and the measurement setup is depicted in Fig. 15. Since the proposed antenna has been integrated with the rectifier, the $S_{11}$ of the rectenna cannot be measured directly. A standard horn antenna R\&S ${ }^{\circ} H F 906$ was used to transmit the RF power. A $30 \mathrm{~dB}$ gain power amplifier (PA) amplifies the signal generated by an RF signal generator (Keithley2920). The rectenna was configured to receive the signal at a distance of 1 meter (in antenna far field). The output DC voltage $\left(V_{D C}\right)$ was measured by using a voltage meter and the output DC power can be obtained by using $P_{\text {out }}=V_{D C^{2}} / R$, where $R$ is the load resistance.

The available power to the transmitting horn antenna was measured by using a power meter, thus the received RF power by the rectenna can be estimated by using the Friis transmission equation [35].

$$
P_{r}=P_{t}+G_{t}+G_{r}+20 \log _{10} \frac{\lambda}{4 \pi r}
$$

where $P_{r}$ is the received power in $\mathrm{dBm}, P_{t}$ is the power obtained from the power meter in $\mathrm{dBm}, G t$ is the realized gain of the transmitting antenna in $\mathrm{dB}, \mathrm{Gr}$ is the realized gain of the 


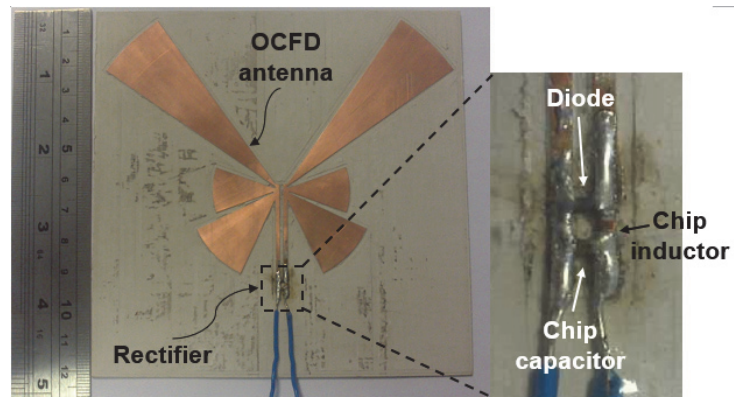

Fig. 14. The fabricated prototype rectenna. The enlarge view of the rectifier is shown as well.

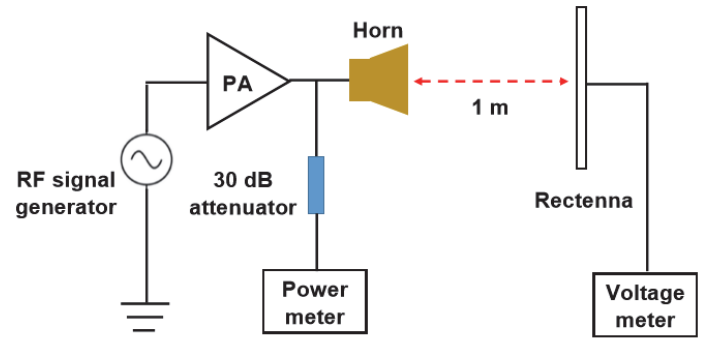

Fig. 15. The measurement setup of the rectenna.

receiving antenna (rectenna) in $\mathrm{dB}, \lambda$ is the wavelength, and $r$ is the distance between the TX and RX antennas ( $r=1 \mathrm{~m})$.

As discussed earlier, the proposed rectenna can reduce the effects of the nonlinearity of the rectifier and match well to a wide range of load impedance values. Thus the rectenna may perform well even when different types of diodes are used. This advantage is normally not available in the conventional rectenna designs, since the input impedance and characteristics of the diodes can be very different. Thus, in order to validate this point, the proposed rectenna was measured by using different types of Schottky diodes such as HSMS2850, HSMS2860, and HSMS2820. The measured conversion efficiency versus input power level is shown in Fig. 16 along with simulated results. High conversion efficiency is obtained in all cases. When the load is selected as $500 \Omega$ and the frequency is selected as $1.85 \mathrm{GHz}$, we have $G t=8.5 \mathrm{dBi}, G r=$ $3.45 \mathrm{dBi}, \lambda=0.162 \mathrm{~m}$, and $r=1 \mathrm{~m}$. Using (9), the correlation between the transmitting power and the receiving power can be obtained as:

$$
\operatorname{Pr}(\mathrm{dBm})=P t(\mathrm{dBm})-25.84 \mathrm{~dB} .
$$

It can be seen that the maximum conversion efficiency and the corresponding input powers of the rectenna are $60 \%$ at 0 $\mathrm{dBm}, 65 \%$ at $5 \mathrm{dBm}, 70 \%$ at $10 \mathrm{dBm}$, and $75 \%$ at $20 \mathrm{dBm}$ for using the Schottky diodes SMS7630, HSMS2850, HSMS2860, and HSMS2820 respectively. The peak efficiency is realized at different input power levels. This is because the breakdown voltages for the selected diodes are different, which are $2 \mathrm{~V}$ (SMS7630), 3.8 V (HSMS2850), $7 \mathrm{~V}$ (HSMS2860), and $15 \mathrm{~V}$ (HSMS2820) respectively. The efficiency is much higher at high input power levels for using the diodes with large breakdown voltages (e.g. HSMS2820), while the efficiency is higher at low input power levels for using the diodes with small forward bias voltages (e.g. SMS7630). The simulated and measured conversion efficiency of the rectenna (using the four
TABLE IV

RECTENNA PERFORMANCE FOR USING DIFFERENT DIODES

\begin{tabular}{ccccc}
\hline \hline $\begin{array}{c}\text { Schottky } \\
\text { diodes name }\end{array}$ & $\begin{array}{c}\text { Simulated input } \\
\text { impedance } \\
\text { under the same } \\
\text { condition }(\Omega)\end{array}$ & $\begin{array}{c}\text { Optimal } \\
\text { input } \\
\text { power } \\
\text { level }\end{array}$ & $\begin{array}{c}\text { Maximum } \\
\text { conversion } \\
\text { efficiency }\end{array}$ & $\begin{array}{c}\text { Optimal } \\
\text { load } \\
\text { resistance } \\
\text { range }(\Omega)\end{array}$ \\
\hline SMS7630 & $173-\mathrm{j} 36$ & $0 \mathrm{dBm}$ & $60 \%$ & $250-1500$ \\
HSMS2850 & $325-\mathrm{j} 57$ & $5 \mathrm{dBm}$ & $65 \%$ & $200-2000$ \\
HSMS2860 & $349-\mathrm{j} 166$ & $10 \mathrm{dBm}$ & $70 \%$ & $200-2500$ \\
HSMS2820 & $82-\mathrm{j} 145$ & $20 \mathrm{dBm}$ & $75 \%$ & $250-3000$ \\
\hline
\end{tabular}

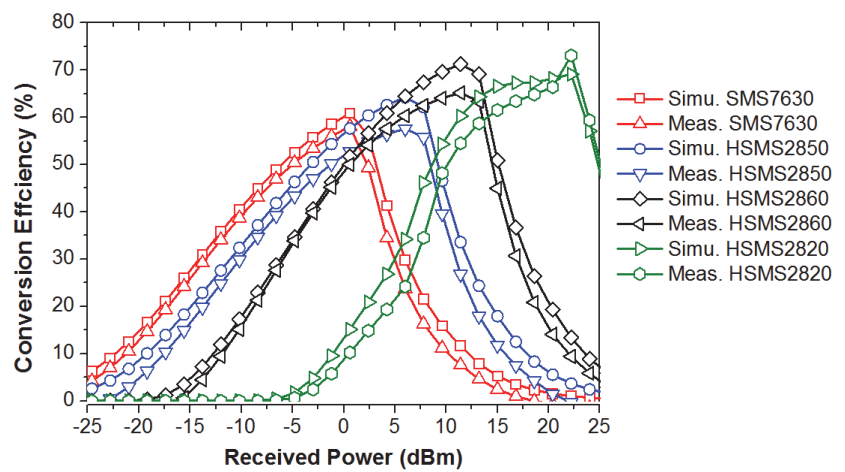

Fig. 16. The simulated and measured conversion efficiency of the rectenna versus input power level for using different types of Schottky diodes. The frequency is $1.85 \mathrm{GHz}$.

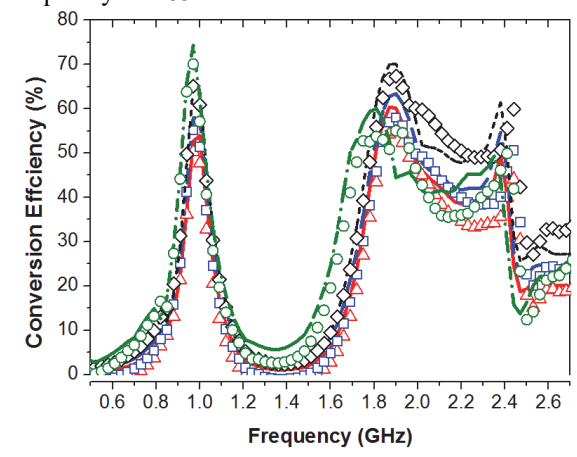

Simu. SMS7630, $0 \mathrm{dBm}$ $\triangle$ Meas. SMS7630, $0 \mathrm{dBm}$ - - Simu. HSMS2850, $5 \mathrm{dBm}$ 口 Meas. HSMS2850, $5 \mathrm{dBm}$ -..- Simu. HSMS2860, $10 \mathrm{dBm}$ $\diamond$ Meas. HSMS2860, $10 \mathrm{dBm}$ -- Simu. HSMS2820,20 dBm Meas HSMS2820, $20 \mathrm{dBm}$

Fig. 17. The simulated and measured conversion efficiency of the rectenna versus frequency for using different types of Schottky diodes at the optimal input power levels. The load resistance is $500 \Omega$.

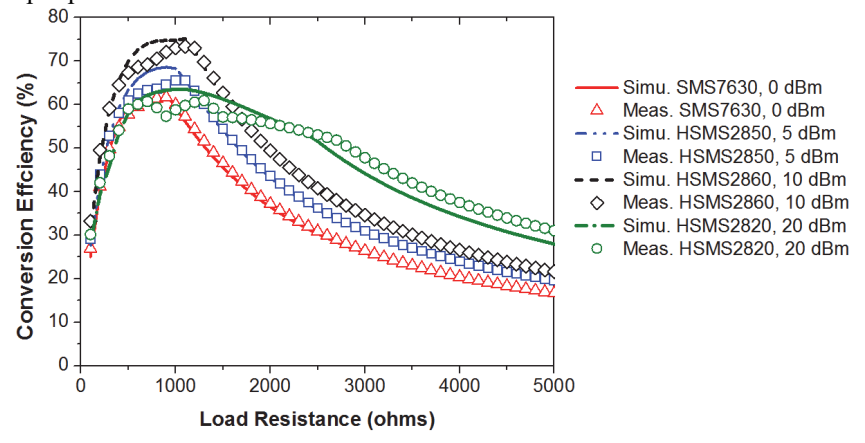

Fig. 18. The simulated and measured conversion efficiency of the rectenna versus load resistance for using different types of Schottky diodes at the optimal input power levels. The frequency is $1.85 \mathrm{GHz}$.

different diodes) are depicted in Fig. 17 as a function of the frequency. The load is still $500 \Omega$ while the input power levels 
TABLE V

COMPARISON OF THE PROPOSED RECTENNA AND RELATED DESIGNS

\begin{tabular}{|c|c|c|c|c|c|c|c|}
\hline Ref. (year) & Frequency $(\mathrm{GHz})$ & $\begin{array}{l}\text { Use of } \\
\text { impedance } \\
\text { matching } \\
\text { networks }\end{array}$ & $\begin{array}{l}\text { Complexity } \\
\text { of the overall } \\
\text { design }\end{array}$ & $\begin{array}{c}\text { Maximum } \\
\text { conversion } \\
\text { efficiency }(\%)\end{array}$ & $\begin{array}{c}\text { Input power level for } \\
\text { conversion } \\
\text { efficiency }>60 \%\end{array}$ & $\begin{array}{l}\text { Optimal load } \\
\text { range with } \\
\text { good } \\
\text { performance } \\
(\mathrm{k} \Omega)\end{array}$ & $\begin{array}{l}\text { Type of } \\
\text { Schottky } \\
\text { diode }\end{array}$ \\
\hline $\begin{array}{c}{[18]} \\
(2015)\end{array}$ & $\begin{array}{c}\text { Four-band } \\
0.9,1.8,2.1,2.4\end{array}$ & Yes & Very complex & 65 at $0 \mathrm{dBm}$ & -5 to $0 \mathrm{dBm}$ & 11 & MSS20-141 \\
\hline $\begin{array}{c}{[19]} \\
(2015)\end{array}$ & $\begin{array}{c}\text { Broad-band } \\
1.8-2.5\end{array}$ & Yes & Complex & 70 at $0 \mathrm{dBm}$ & -7 to $0 \mathrm{dBm}$ & 14.7 & SMS7630 \\
\hline $\begin{array}{c}{[20]} \\
(2015) \\
\end{array}$ & $\begin{array}{l}\text { Dual-band } \\
0.915,2.45\end{array}$ & Yes & Complex & 70 at $0 \mathrm{dBm}$ & -5 to $0 \mathrm{dBm}$ & $0.5-3$ & SMS7630 \\
\hline $\begin{array}{c}{[23]} \\
(2012) \\
\end{array}$ & $\begin{array}{c}\text { Tunable } \\
0.9-2.45 \\
\end{array}$ & Yes & Very complex & 80 at $30 \mathrm{dBm}$ & $\begin{array}{c}\text { Tunable } \\
5 \text { to } 30 \mathrm{dBm}\end{array}$ & $1-4$ & Tunable \\
\hline $\begin{array}{c}24] \\
(2016)\end{array}$ & $\begin{array}{c}\text { Six-band } \\
0.55,0.75,0.9,1.85,2.15,2.45\end{array}$ & Yes & Very complex & 68 at $-5 \mathrm{dBm}$ & -5 to $0 \mathrm{dBm}$ & $10-75$ & SMS7630 \\
\hline $\begin{array}{c}{[25]} \\
(2012)\end{array}$ & $\begin{array}{c}\text { Single-band } \\
2.45\end{array}$ & No & Simple & 70 at $-5 \mathrm{dBm}$ & -10 to $5 \mathrm{dBm}$ & 2.8 & HSMS2852 \\
\hline $\begin{array}{c}{[26]} \\
(2004)\end{array}$ & $\begin{array}{c}\text { Broad-band } \\
2-18\end{array}$ & No & Medium & 20 at $17 \mathrm{dBm}$ & Not available & 0.6 & SMS7630 \\
\hline $\begin{array}{l}\text { This work } \\
\text { (2016) }\end{array}$ & $\begin{array}{c}\text { Broad-band } \\
0.9-1.1,1.8-2.5\end{array}$ & No & Simplest & 75 at $20 \mathrm{dBm}$ & $\begin{array}{c}\text { Tunable } \\
0 \text { to } 23 \mathrm{dBm}\end{array}$ & $0.2-2$ & Tunable \\
\hline
\end{tabular}

are selected as the optimal input powers for these diodes (e.g. 0 $\mathrm{dBm}$ for SMS7630, $5 \mathrm{dBm}$ for HSMS2850, $10 \mathrm{dBm}$ for HSMS2860, and $20 \mathrm{dBm}$ for HSMS2820). Note that in the measurements, the correlation between the transmitting power and the receiving power (as given in (9)) might be changed if the frequencies are different. Thus the transmitting power should be tuned to make sure that the received power is approximately a constant value in the broadband (e.g. $0 \mathrm{dBm}$ for the frequencies from 0.9 to $3 \mathrm{GHz}$ ).

From the results in Fig. 17, it can be seen that the rectenna is still of broadband performance (1.8 to $2.5 \mathrm{GHz}$ ) when using different diodes, and the conversion efficiency is constantly high over the frequency bandwidth of interest for the selected input power levels. Figs. 16 and 17 have shown a good agreement between the simulated and measured results.

Fig. 18 shows the simulated and measured conversion efficiency by using different load resistances. The frequency is selected as $1.85 \mathrm{GHz}$ while the input power levels are still set as the optimal input powers. In reality, the load impedance may vary over a large range in different applications, thus it is important to reduce the sensitivity of efficiency vs. load variation in a nonlinear system (rectenna). From Fig. 18 it can be seen that, when using different diodes, the efficiency of the rectenna is constantly high (from $40 \%$ to $75 \%$ ) for the load values between $200 \Omega$ and $2000 \Omega$, then the efficiency starts to decease due to the impedance mismatch between the antenna and the rectifier. It demonstrates that the nonlinear effects have been reduced over the load range from 200 to $2000 \Omega$. For other load values, the details of the rectenna can be modified to achieve good performance.

According to the results in Figs. 16-18, the performance of the rectenna by using different diodes is summarized in Table IV. The simulated input impedance of the rectifier is shown under the same condition (frequency: $1.85 \mathrm{GHz}$, input power: $10 \mathrm{dBm}$, and load: $500 \Omega$ ). The impedance is very different for different types of diodes, but our rectenna can still be well configured with these diodes without using matching networks. It is demonstrated that the proposed broadband rectenna can work well in different operating conditions. The non-linear effects have been reduced. The matching networks have indeed been eliminated. In addition, the optimal input power level of the device is tunable (from 0 to $23 \mathrm{dBm}$ ) by selecting appropriate diodes so that the conversion efficiency of the broadband rectenna can be always higher than $60 \%$ (as shown in Fig. 16). This is very important for WPT or WEH used in practice.

A comparison between our rectennna and other related work is shown in Table V. It can be seen that our design seems to be the only one without using the matching networks, but still achieves high conversion efficiency over a relatively wide frequency band. The conversion efficiency of our design is comparable with that of the other work used matching networks, while the performance of the rectenna is reasonably well in a range of input powers and load impedance. In addition, our device is also the only one which can use different types of diodes without changing any other part of the circuit. The structure of our design is the simplest for broadband rectennas with similar performance. The proposed rectenna is of good industrial value due to its simplicity and universality, and is of good practical value due to its consistent performance in different operating conditions.

Also, the proposed concept for eliminating the matching networks is not just limited in the presented design, and can also be used in other similar non-linear systems.

\section{CONCLUSION}

A novel method for eliminating the matching network of broadband rectennas has been presented. An OCFD antenna has been designed, where the antenna impedance can be tuned to directly match with the rectifier. The proposed rectenna is of a broad bandwidth and high efficiency, and has excellent performance in different operating conditions. The measured performance has shown that the operating frequencies of the experimental rectenna are from 0.9 to $1.1 \mathrm{GHz}$ and from 1.8 to $2.5 \mathrm{GHz}$ (which are the typical cellular mobile, WLAN and ISM bands), while the maximum conversion efficiency is up to 
$75 \%$ and the optimal input power range is tunable from $0 \mathrm{dBm}$ to $23 \mathrm{dBm}$ by selecting appropriate diodes. In addition, the rectenna has a very simple structure and low cost. Considering the excellent overall performance of the proposed rectenna, it is suitable for high efficiency WPT and WEH applications. The design concept is easy to follow while its details can be optimized for different applications.

\section{ACKNOWLEDGMENT}

The authors would like to thank the anonymous reviewers for their constructive feedback of this paper. The authors would also like to thank Prof. S. Hall from the University of Liverpool, for the refinement of the manuscript.

\section{REFERENCES}

[1] S. Carreon-Bautista, A. Eladawy, A. N. Mohieldin, and E. Sanchez-Sinencio, "Boost converter with dynamic input impedance matching for energy harvesting with multi-array thermoelectric generators," IEEE Trans. Ind. Electron., vol. 61, no. 10, pp. 5345-5353, Oct. 2014.

[2] J. Jeong and D. Jang, "Design technique for harmonic-tuned RF power oscillators for high-efficiency operation," IEEE Trans. Ind. Electron., vol. 62, no. 1, pp. 221-228, Jan. 2015.

[3] J. Kim, D.-H. Kim, and Y.-J. Park, "Analysis of capacitive impedance matching networks for simultaneous wireless power transfer to multiple devices," IEEE Trans. Ind. Electron., vol. 62, no. 5, pp. 2807-2813, May 2015 .

[4] K. Song and Q. Xue, "Ultra-wideband ring-cavity multiple-way parallel power divider," IEEE Trans. Ind. Electron., vol. 60, no. 10, pp. 4737 4745, Oct. 2013

[5] K. Rawat and F. M. Ghannouchi, "Design methodology for dual-band Doherty power amplifier with performance enhancement using dualband offset lines," IEEE Trans. Ind. Electron., vol. 59, no. 12, pp. 4831-4842, Dec. 2012

[6] X. Wang, X. K. Guan, and S. Q. Fan, "ESD-protected power amplifier design in CMOS for highly reliable RFICs," IEEE Trans. Ind. Electron., vol. 58, no. 7, pp. 2736-2743, Jun. 2011.

[7] R. Johari, J. V. Krogmeier, and D. J. Love, "Analysis and practical considerations in implementing multiple transmitters for wireless power transfer via coupled magnetic resonance," IEEE Trans. Ind. Electron., vol. 61, no. 4, pp. 1174-1183, Apr. 2014.

[8] L. Chen, Y. C. Zhou, and T. J. Cui, "An optimizable circuit structure for high-efficiency wireless power transfer," IEEE Trans. Ind. Electron., vol 60, no. 1, pp. 339-349, Jan. 2013.

[9] H. J. Visser and R. J. M. Vullers, "RF energy harvesting and transport for wireless sensor network applications: Principles and requirements," Proc. IEEE, vol. 101, no. 6, pp. 1410-1423, Jun. 2013.

[10] S. Cheon, Y.-H. Kim, S.-Y. Kang, M. L. Lee, J.-M. Lee, and T. Zyung, "Circuit-model-based analysis of a wireless energy-transfer system via coupled magnetic resonances," IEEE Trans. Ind. Electron., vol. 58, no. 7, pp. 2906-2914, Jul. 2011.

[11] J. Colomer-Farrarons, P. Miribel-Català, A. Saiz-Vela, and J. Samitier "A multiharvested self-powered system in a low-voltage low-power technology," IEEE Trans. Ind. Electron., vol. 58, no. 9, pp. 4250-4263, Sep. 2011.

[12] Y. Huang, N. Shinohara, and T. Mitani, "A constant efficiency of rectifying circuit in an extremely wide load range," IEEE Trans. Microw. Theory Tech., vol. 62, no. 4, pp. 986-993, Apr. 2014.

[13] P. Lu, X. Yang, J. Li, and B. Wang, "A compact frequency reconfigurable rectenna for 5.2- and 5.8-GHz wireless power transmission," IEEE Trans. Power Electron., vol. 30, no. 11, pp. 6006-6010, Nov. 2015.

[14] J. O. McSpadden, F. Lu, and K. Chang, "Design and experiments of a high conversion efficiency 5.8-GHz rectenna," IEEE Trans. Microw. Theory Tech., vol. 46, no. 12, pp. 2053-2060, Dec. 1998.

[15] H. Sun, Y.-x. Guo, M. He and Z. Zhong, "A dual-band rectenna using broadband Yagi antenna array for ambient RF power harvesting," IEEE Antennas and Wireless Propa. Lett., vol. 12, pp. 918-921, 2013.

[16] K. Niotaki, S. Kim, S. Jeong, A. Collado, A. Georgiadis, and M. Tentzeris, "A compact dual-band rectenna using slot-loaded dual band folded dipole antenna," IEEE Antennas and Wireless Propa. Lett. vol. 12, pp. 1634-1637, 2013.

[17] R. Scheeler, S. Korhummel and Z. Popovic, "A dual-frequency ultralow-power efficient 0.5-g rectenna," IEEE Microwave Mag., vol. 15, no. 1, pp. 109-114, Jan. 2014.

[18] V. Kuhn, C. Lahuec, F. Seguin, and C. Person, "A multi-band stacked RF energy harvester with rf-to-dc efficiency up to $84 \%$," IEEE Trans. Microw. Theory Tech., vol. 63, no. 5, pp. 1768-1778, May 2015.

[19] C. Song, Y. Huang, J. Zhou, J. Zhang, S. Yuan and P. Carter, "A high-efficiency broadband rectenna for ambient wireless energy harvesting," IEEE Trans. Antennas Propag., vol. 63, no. 8, pp. 34863495, May 2015.

[20] K. Niotaki, A. Georgiadis, A. Collado, and J. S. Vardakas, "Dual-band resistance compression networks for improved rectifier performance," IEEE Trans. Microw. Theory Tech., vol. 62, no. 12, pp. 3512-3521, Nov. 2015.

[21] Y. Han, O. Leitermann, D. A. Jackson, J. M. Rivas, and D. J. Perreault, "Resistance compression networks for radio-frequency power conversion," IEEE Trans. Power Electron., vol. 22, no. 1, pp. 41-53, Jan. 2007.

[22] T. Paing, J. Shin, R. Zane, and Z. Popovic, "Resistor emulation approach to low-power RF energy harvesting," IEEE Trans. Power Electron., vol. 23, no. 3, pp. 1494-1501, Mar. 2008.

[23] V. Marian, B. Allard, C. Vollaire, and J. Verdier, "Strategy for microwave energy harvesting from ambient field or a feeding source," IEEE Trans. Power Electron., vol. 27, no. 11, pp. 4481-4491, Nov. 2012.

[24] C. Song, Y. Huang, P. Carter, J. Zhou, S. Yuan, Q. Xu, and K. Muayad, "A novel six-band dual CP rectenna using improved impedance matching technique for ambient RF energy harvesting," IEEE Trans. Antennas Propag., vol. 64, no. 7, pp. 3160-3171, Jul. 2016.

[25] H. Sun, Y.-x. Guo, M. He and Z. Zhong, "Design of a high-efficiency $2.45-\mathrm{GHz}$ rectenna for low-input-power energy harvesting," IEEE Antennas and Wireless Propaga. Lett., vol. 11, pp. 929-932, 2012.

[26] J. A. Hagerty, F. B. Helmbrecht, W. H. McCalpin, R. Zane and Z. B. Popovic, "Recycling ambient microwave energy with broad-Band rectenna Arrays," IEEE Trans. Microw. Theory Tech., vol. 52, no. 3, pp. 1014-1024, Mar. 2004.

[27] Z. K. Ma, and G. A. E. Vandenbosch "Wideband harmonic rejection filtenna for wireless power transfer," IEEE Trans. Antennas Propag., vol. 62, no. 1, pp. 371-377, Oct. 2013.

[28] N. Shinohara and Y. Zhou, "Development of rectenna with high impedance and high Q antenna," in 2014 Asia-Pacific Microwave Conference, pp. 600-602, Nov. 2014.

[29] H. Miyagoshi, K. Noguchi, K. Itoh and J. Ida. "High-impedance wideband folded dipole antenna for energy harvesting applications," in Antennas and Propagation (ISAP), 2014 International Symposium on, pp. 601-602, Dec. 2014.

[30] H. Chu, Y.-X. Guo, and Z. Wang, "60-GHz LTCC wideband vertical offcenter dipole antenna and arrays," IEEE Trans. Antennas Propag., vol. 61, no. 1, pp. 153-161, Jan. 2013.

[31] R. Li, L. Pan, and Y. Cui, "A novel broadband circularly polarized antenna based on off-center-fed dipoles," IEEE Trans. Antennas Propag., vol. 63, no. 12, pp. 5296-5304, Dec. 2015.

[32] J. Belrose, P. Bouliane, "The off-center-fed dipole revisited: a broadband, multiband antenna," QST Magazine. vol. 74, no. 8, pp. 28-34. 1990.

[33] J. Guo, H. Zhang, and X. Zhu, "Theoretical analysis of RF-DC conversion efficiency for class-F rectifiers," IEEE Trans. Microw. Theory Techn., vol. 62, no. 4, pp. 977-985, Apr. 2014.

[34] Surface Mount Mixer and Detector Schottky Diodes, Data Sheet. Skyworks Solutions, Inc., Woburn, MA, USA, 2013.

[35] S. Ladan, A. B. Guntupalli, and K. Wu, "A high-efficiency $24 \mathrm{GHz}$ rectenna development towards millimeter-wave energy harvesting and wireless power transmission," IEEE Trans. Circuits Syst. I, Reg. Papers, vol. 61, no. 12, pp. 3358-3366, Dec. 2014.

[36] J. D. Kraus and R. J. Marhefka, Antennas: for all applications, 3rd ed., McGraw-Hill series in electrical engineering, U.S., 2001.

[37] S. Schellkunoff, Electromagnetic waves, Van Nostrand, New York, 1943.

[38] E. Spingola, "Multiband HF antennas, part 3, Windom and OCF dipole," The Communicator. Mississauga. vol. 13, no. 4, pp. 7-11. 2010. 


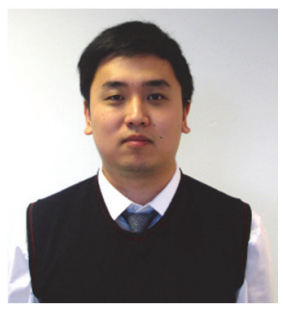

Chaoyun Song (S'16) received the B.Eng. (Hons.) degree in telecommunication engineering from Xi'an Jiaotong-Liverpool University, Suzhou, China, in 2012, and the M.Sc. degree with distinction in microelectronics and telecommunication from The University of Liverpool, Liverpool, U.K., in 2013 , where he is currently pursuing the Ph.D. degree in wireless communications and radio frequency engineering.

His current research interests include rectifying antenna, circular polarization antenna, power management circuit, wireless power transfer and energy harvesting, and wearable antennas. Mr. Song has been a regular reviewer of IEEE TRANSACTIONS ON CIRCUITS AND SYSTEMS I: REGULAR PAPERS, IEEE TRANSACTIONS ON MICROWAVE THEORY AND TECHINQUES, and IEEE ANTENNAS AND WIRELESS PROPAGATION LETTERS.

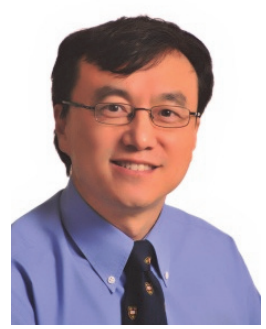

Yi Huang (S'91-M'96-SM'06) received the D.Phil. degree in communications from the University of Oxford, Oxford, U.K., in 1994.

$\mathrm{He}$ has been conducting research in the areas of wireless communications, applied electromagnetics, radar and antennas for the past 25 years. He joined the Department of Electrical Engineering \& Electronics, the University of Liverpool, U.K., as a Faculty member in 1995, where he is now a Full Professor in Wireless Engineering. He has published over 200 refereed papers in leading international journals and conference proceedings, and is the principal author of the popular book Antennas: from Theory to Practice (Wiley, 2008).

Prof. Huang has been an Editor, Associate Editor, or Guest Editor of four of international journals. He is at present the Editor-in-Chief of Wireless Engineering and Technology, an Associate Editor of IEEE Antennas and Wireless Propagation letters, a UK National Rep of European COST-IC1102, an Executive Committee Member of the IET Electromagnetics PN, and a Fellow of IET, U.K.

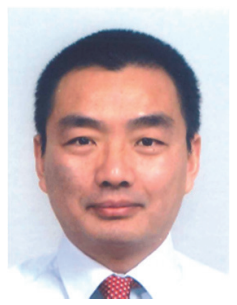

Jiafeng Zhou received the B.Sc. degree in radio physics from Nanjing University, Nanjing, China, in 1997, and the Ph.D. degree from the University of Birmingham, Birmingham, U.K., in 2004. His Ph.D. research concerned high-temperature superconductor microwave filters.

$\mathrm{He}$ was with the National Meteorological Satellite Centre of China, Beijing, China, from 1997, for two and a half years, where he was involved in the development of communication systems for Chinese geostationary meteorological satellites. From 2004 to 2006, he was a Research Fellow with the University of Birmingham, where he was involved in phased arrays for reflector observing systems. $\mathrm{He}$ then moved to the Department of Electronic and Electrical Engineering, University of Bristol, Bristol, U.K., until 2013, where he was involved in the development of highly efficient and linear amplifiers. He is currently with the Department of Electrical Engineering and Electronics, The University of Liverpool, Liverpool, U.K. His current research interests include microwave power amplifiers, filters, electromagnetic energy harvesting, and wireless power transfer.

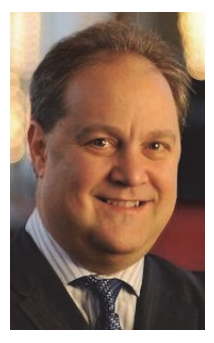

Paul Carter received the B.Sc. degree (Hons.) in physics from the University of Manchester, U.K., in 1987, the M.Sc. degree (Eng.) in microelectronic systems and telecommunications, in 1988, and the Ph.D. degree in electrical engineering and electronics, in 1991 both from the University of Liverpool, U.K.

$\mathrm{He}$ is the President and CEO of Global Wireless Solutions, Inc. (GWS), Dulles, VA, USA, a leading independent benchmarking solution vendor for the wireless industry. With more than 25 years of experience in the cellular network industry, he founded Global Wireless Solutions to provide operators with access to in-depth, accurate network benchmarking, analysis, and testing. Prior to GWS, he directed business development and CDMA engineering efforts for LLC, the world's largest independent wireless engineering company.

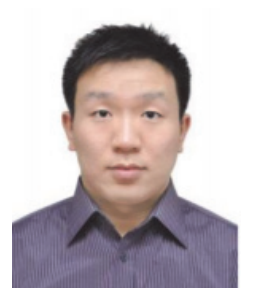

Sheng Yuan received B.Eng. degree (first class) in microelectronics and telecommunication engineering from the University of Liverpool, UK in 2012 and received the $\mathrm{PhD}$ degree in electrical engineering \& electronics from the University of Liverpool, UK, in 2016.

$\mathrm{He}$ is now with the Department of Intelligent Transportation System, Arup Group Limited, Newcastle, UK. His research interests include wireless energy harvesting, ferromagnetic material, indoor navigation system, energy management circuit, wireless power transfer, RFID and intelligent transportation system.

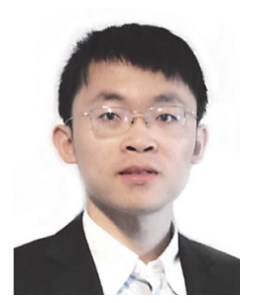

Qian Xu received the B.Eng. and M.Eng. degrees from the Department of Electronics and Information, Northwestern Polytechnical University, Xi'an, China, in 2007 and 2010, and received the $\mathrm{PhD}$ degree in electrical engineering from the University of Liverpool, U.K, in 2016. He is currently an Associate Professor at the College of Electronic and Information Engineering, Nanjing University of Aeronautics and Astronautics, China.

He worked as a RF engineer in Nanjing, China in 2011, an Application Engineer at CST Company, Shanghai, China in 2012 and a Research Assistant at the University of Liverpool, UK in 2016. His research interests include statistical electromagnetics, reverberation chamber, computational electromagnetics, and anechoic chamber.

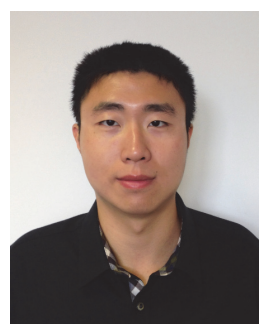

Zhouxiang Fei was born in Xi'an, China, in 1990. He received his B.Eng. degree in electronics and information engineering from Northwestern Polytechnical University, Xi'an, China, in 2012 and the M.Sc. degree with distinction in wireless communications from the University of Southampton, Southampton, U.K., in 2013 . He is currently working toward the Ph.D. degree at the University of Liverpool, Liverpool, U.K.

His research interests include numerical and experimental studies of crosstalk in complex cable bundles, with a particular emphasis on considering parameter variability using efficient statistical approaches. He was the recipient of the student scholarship from the IEEE EMC Society to attend the 2016 IEEE International Symposium on EMC, Ottawa, Canada, July 2016. He was also selected as the BEST EMC PAPER FINALIST for the 2016 IEEE International Symposium on EMC. 